\title{
T2 and DWI in Pilocytic and Pilomyxoid Astrocytoma with Pathologic Correlation
}

\author{
M. Horger, M.N. Vogel, R. Beschorner, U. Ernemann, J. Wörner, M. Fenchel, F. \\ Ebner, T. Nägele, S. Heckl
}

\begin{abstract}
Objective: To quantify and compare T2 signal and apparent diffusion coefficient (ADC) in pilocytic and pilomyxoid astrocytoma (PA and PMA) and correlate results with myxoid content. Methods: Echo-planar diffusion weighted images (DWI) and standard magnetic resonance imaging (MRI) findings were reviewed retrospectively in patients with PA $(n=34)$ and PMA ( $n=8)$. Regions of interest (ROIs) were drawn on ADC maps within tumor parts with lowest ADC values. Apparent diffusion coefficient values in tumor were normalized to those in cerebrospinal fluid (ADC/CSF). The ratio of T2 signal intensity in solid tumor parts to CSF (T2/CSF) was registered. Myxoid matrix was histologically quantified retrospectively in 8 PMAs and 17 PAs and correlated with imaging findings. Results: Mean ADC/CSF for PA and PMA was $0.53 \pm 0.10$ and $0.69 \pm 0.10(\mathrm{p}<0.01)$. Mean T2/CSF for PA and PMA was $0.78 \pm 0.19$ and $0.93 \pm 0.09(\mathrm{p}<0.01)$. Mean proportion of myxoid tumor matrix in PA was $50 \%$ (range, $10-100 \%$ ) and $93 \%$ (range, $90-100 \%$ ) in PMA $(\mathrm{p}=0.004)$. Eight patients (32\%; all PA) had less than 50\% myxoid content and 17 (68\%; 8 PA; 9 PMA) had more. There was positive correlation of $\mathrm{ADC} / \mathrm{CSF}, \mathrm{T} 2 / \mathrm{CSF}$ and $\mathrm{ADC}\left(\mathrm{r}^{2}=0.61,0.65\right.$ and 0.60 respectively) and significant difference between the groups with more and less than $50 \%$ myxoid content ( $\mathrm{p}=0.01$ for $\mathrm{ADC} / \mathrm{CSF}$ and $\mathrm{T} 2 / \mathrm{CSF}$ and $\mathrm{p}=0.02$ for ADC). Conclusions: General imaging features of PA and PMA are non-specific, ADC values and T2 signal intensity are generally higher in the latter, reflecting the proportion of myxoid matrix in these tumors.
\end{abstract}

RÉSUMÉ: T2 et DWI dans les astrocytomes pilocytiques et pilomyxö̈des - Corrélation anatomopathologique. Objectif : Le but de l'étude était de quantifier et de comparer le signal T2 et le coefficient de diffusion apparent (CDA) dans l'astrocytome pilocytique et l'astrocytome pilomyxoïde (AP et APM) et de corréler les résultats avec le contenu myxoïde de la tumeur. Méthode : Les images écho-planaires pondérées en diffusion et les observations à l'IRM conventionnelle ont été révisées rétrospectivement chez des patients atteints d'AP $(n=34)$ et d'APM $(n=8)$. Les régions d'intérêt (RI) ont été reproduites sur des cartes CDA dans les parties de la tumeur présentant les valeurs CDA les plus faibles. Les valeurs CDA dans les tumeurs ont été normalisées par rapport à celles du liquide céphalo-rachidien (CDA/LCR). Le ratio de l'intensité du signal T2 dans les parties solides de la tumeur par rapport du LCR (T2/LCR) a été enregistré. La matrice myxoïde a été quantifiée rétrospectivement au point de vue anatomopathologique dans 8 APM et $17 \mathrm{AP}$ et corrélée aux observations d'imagerie. Résultats : La moyenne du ratio CDA/LCR était 0,53 $\pm 0,10$ pour l'AP et 0,69 $\pm 0,10$ pour l'APM (p $<0,01$ ). La proportion moyenne de matrice tumorale myxö̈de dans l'AP était de 50\% (écart 10 à 100\%) et de $93 \%$ (écart de 90 à 100\%) dans l'APM (p $=0,004)$. La tumeur chez huit patients $(32 \%$, tous atteints d'AP) contenait moins de $50 \%$ de matrice tumorale myxoïde et chez 17 patients $(68 \%$ dont 8 $\mathrm{AP}$ et $9 \mathrm{APM})$ en contenait davantage. Il existait une corrélation positive entre le ratio CDA/LCR, T2/LCR et CDA ( $22=0,61,0,65$ et 0,60 respectivement) et une différence significative entre les groupes ayant plus ou moins de $50 \%$ de contenu myxoïde ( $\mathrm{p}=0,01$ pour CDA/LCR et T2/LCR et $\mathrm{p}=0,02$ pour $\mathrm{CDA}$ ). Conclusions : Les caractéristiques générales à l'imagerie de l'AP et de l'APM ne sont pas spécifiques. Les valeurs du CDA et l'intensité du signal T2 sont généralement plus élevées dans l'APM, ce qui reflète la proportion de matrice myxoïde présente dans ces tumeurs.

Can J Neurol Sci. 2012; 39: 491-498

Primary brain tumors are the most frequent solid tumors in children representing almost $20 \%$ of all pediatric tumors ${ }^{1}$. Among them, pilocytic astrocytoma (PA) is one of the leading entities known for its benign character and classified as World Health Organization (WHO) grade I. Depending on its primary location; PA may pose considerable differential diagnostic problems, despite some established imaging features ${ }^{2}$. Whereas the features of juvenile PA, such as a circumscribed mass, usually partly cystic with a mural enhancing nodule, have been well described, the imaging characteristics of their adult counterparts are less specific. Moreover, even in juvenile PA, $50 \%$ of tumors present as entirely solid or more rarely as entirely cystic masses and are thus referred to as atypical.

Pilomyxoid astrocytoma (PMA) is a clinically and histologically described recent variant and considered an infantile type of PA, characterised by a higher rate of recurrences and more frequent dissemination in the cerebrospinal fluid (CSF) and is therefore classified as WHO grade $\mathrm{II}^{3}$. In general, however, morphologic imaging features do not essentially differ from those of PA, except for the myxoid background in the solid parts of PMA which is expected to result in an increased T2 signal intensity ${ }^{4,5}$. Contrast enhancement in PMA is reported to be variable, in the current literature.

From the Department of Diagnostic and Interventional Radiology (MH, MNV, JW), Institute for Brain Research (RB), Department of Diagnostic and Interventional Neuroradiology (UE, MF, TN, SH), Department of Neurosurgery (FE), EberhardKarls-University, Tübingen; Department of Neuroradiology (MNV), University of Heidelberg, Heidelberg, Germany.

Received December 6, 2011. Final Revisions Submitted March 2, 2012. Correspondence to: Monika N. Vogel, Department of Neuroradiology, University of Heidelberg, Heidelberg, Germany. Email: m.n.a.vogel@web.de 
Diffusion-weighted magnetic resonance (MR) imaging (DWI) is an adjunct to the conventional MR-technique capable of delivering information on the macromolecular structure of a tumor and its impact on water diffusivity. Hence tumors that are highly cellular, presenting large nuclei and scarce cytoplasm are expected to exhibit significant restriction of water diffusivity compared to those that possess a large extracellular space. Due to the difficulties in differentiation of primary central nervous system (CNS) tumors, diffusion coefficients have been increasingly implemented in routine diagnosis and allow for accurate discriminatory properties in some entities ${ }^{6-8}$. Juvenile PA has been reported to show no remarkable restriction of water diffusivity, with ADC values lying above those of its differentials (e.g. medulloblastoma) ${ }^{9}$. The advent of the recently described PA variant, the PMA, incites the discussion about its DWI characteristics ${ }^{10,11}$. Hence the purpose of this study was to assess and compare T2 and ADC values of PA and its variant PMA and to correlate the results with the myxoid content of tumors.

To our knowledge, this study represents the first to quantify T2 and ADC values in PA and PMA in correlation with the histologically determined myxoid content in the tumor matrix.

\section{Materials ANd Methods}

\section{Patient characteristics}

A waiver for informed consent was granted by our institutional review board because of the retrospective and anonymous character of this study. A search of our institution's electronic medical record database from October 2003 through December 2010 was performed for patients who underwent neurosurgery for either PA or PMA. Of these patients a total of 42 (22 male, 18 female; mean age 18.4 years; age range $0-73$ years) had undergone magnetic resonance imaging (MRI) of the head including DWI. Thirty-two children $(\mathrm{PA}=26, \mathrm{PMA}=6)$ and ten adults $(\mathrm{PA}=8, \mathrm{PMA}=2)$ were included. The patients displayed 33 WHO grade I PAs, 1 WHO grade III anaplastic PA, 7 PMAs WHO grade II and 1 WHO grade III anaplastic PMA with anaplastic features. All images of these 42 patients were reviewed retrospectively with special respect to the evaluation of $\mathrm{T} 2$ signal intensity and its ratio to CSF (T2/CSF) as well as to the quantification of water diffusivity as seen on ADC maps. Patient identifiers were removed from image data at the earliest opportunity prior to analysis.

\section{Imaging}

Conventional MR imaging was performed on 1.5T MR units with a protocol that included axial non-contrast T1-weighted ( TR=461 msec, TE=12 msec), axial fast spin-echo T2-weighted (TR=4000-5560 msec, TE=91-108 msec), axial fluid-attenuated inversion recovery (FLAIR)(TR=8800 $\mathrm{msec}, \mathrm{TE}=118 \mathrm{msec}$, $\mathrm{TI}=2200 \mathrm{msec})$, as well as post-Gadolinium $(\mathrm{Gd})$ multiplanar T1weighted images $(\mathrm{TR}=584-620 \mathrm{msec}, \mathrm{TE}=17 \mathrm{msec})$. The postGd T1-weighted sequence was performed in both transverse and coronal planes with parameters that were identical to nonenhanced T1-weighted sequences after intravenous administration of $0.2 \mathrm{mmol}$ per kilogram of body weight gadopentetate dimeglumine (Magnevist; Bayer Healthcare, Berlin, Germany) or $0.1 \mathrm{mmol}$ per kilogram of body weight gadobutrol (Gadovist, Bayer HealthCare, Berlin Germany). Slice thickness ranged between 4 and $5 \mathrm{~mm}$.
Diffusion-weighted MR imaging was performed before the administration of contrast material in the transverse plane by using an echo-planar imaging sequence with the following parameters: repetition time (TR) 3900-4800 msec, echo time (TE) 76-119 msec (depending on the scanner), diffusion gradient encoding in three orthogonal directions $(b=0,500$ and 1000 $\mathrm{sec} / \mathrm{mm} 2$ ), field of view (FOV) $230 \times 230 \mathrm{~mm}^{2}$, matrix size 128 x 128, slice thickness $5 \mathrm{~mm}$, and receiver bandwidth (BW) 1302 Hertz/Pixel (Hz/Px).

\section{Image analysis}

Magnetic resonance signal characteristics of the tumors were evaluated on T1- and T2-weighted images and rated as hyperintense, isointense, or hypointense relative to normal gray matter. The degree of enhancement was categorized as absent, mild or strong and the pattern of enhancement scored as homogeneous or heterogeneous. The presence of perifocal edema was graded as absent, or present. The presence of cystic tumor parts was scored as absent, present or extensive.

For each patient two regions of interest (ROIs) about $40 \mathrm{~mm}^{2}$ were positioned manually within solid tumor parts on ADCmaps and $\mathrm{T} 2$ weighted images to quantify $\mathrm{T} 2$ signal intensity and ADC. For ADC-quantification ROIs were positioned in tumor parts that showed the lowest ADC. All values including ROI size were calculated automatically. T2 signal intensity was expressed in artificial units (a.u.) and ADC values were expressed in $10^{-3}$ $\mathrm{mm}^{2} / \mathrm{s}$. Volume averaging with cystic or necrotic regions that might influence measurements was avoided. Reference values were obtained by placing ROIs in the ipsilateral ventricle. The $\mathrm{ADC}$ values of two patients with PA were not included in the final statistic evaluation due to their small size and difficult delineation of tumor on DWI as they exhibited no restriction of water diffusivity. The ratio of the mean values to the mean reference values of CSF was then calculated (T2/CSF and $\mathrm{ADC} / \mathrm{CSF}$ ). These two ratios were calculated additionally in order to minimize the influence of different scanners on measured signal intensities and ADC values. We decided not to use tumor/brain parenchyma ratios due to the broad age spectrum of our patients and associated pathologies in the adults. Two experienced radiologist (HS and HM) performed these measurements independently and blinded to the histological subtype of tumors.

\section{Histological analysis}

Histopathological diagnosis was performed in line with the current WHO classification of tumors of the central nervous system $^{3}$. The diagnosis was made in consensus by at least two fellows in neuropathology with at least eight years of experience in the field of oncologic neuropathology. Cases that were diagnosed prior to the publication of the current WHO classification in 2007 were reevaluated. Accordingly, in PA (WHO grade I) the cellularity is usually low to moderate and tumors often exhibit a biphasic pattern with varying proportions of compact bipolar cells and loose-textured areas. Mitoses are absent or rare and no/rare infarct-like necroses are found. Glomeruloid vascular proliferations, similar to those seen in glioblastomas, are a prominent feature and not a sign of malignancy in PA. Rosenthal fibers, eosinophilic granular bodies and myxoid/mucoid changes are also common in PA (Figures 1a-b). In one case, PA showed 


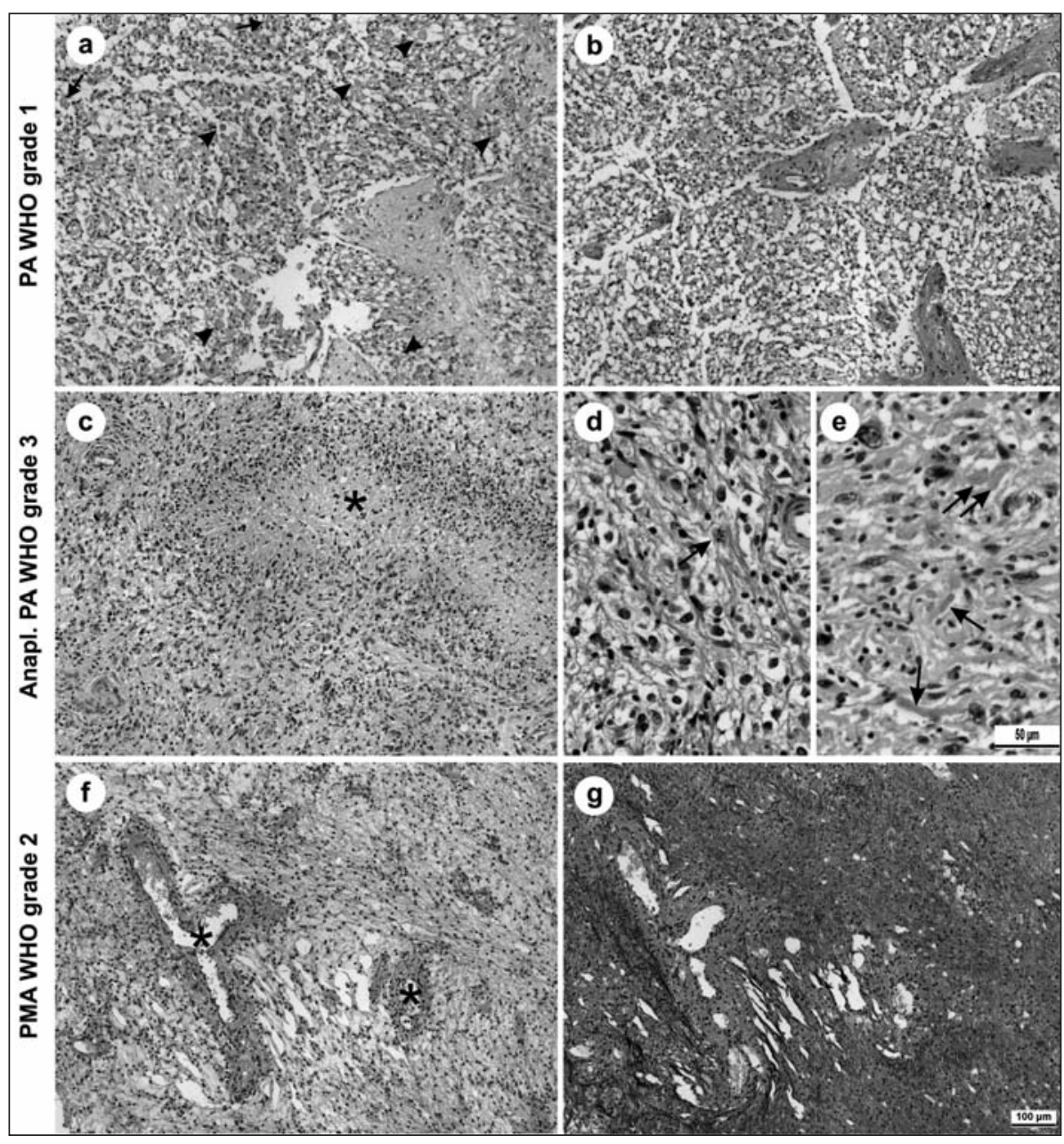

Figure 1: Histological features of $P A$, anaplastic PA and PMA. Typical PA (WHO grade I) show a moderatly increased cellularity, some rosenthal fibres (a; arrows), numerous eosinophilic granular bodies (a; arrow heads) and variable areas with a myxoid matrix. Rarely PA may show anaplastic features such as pseudopalisading necrosis (c; asterisk), increased mitotic activity (d; arrow) and pleomorphism (e). Note numerous rosenthal fibers in a anaplastic PA (e; arrows). In PMA the tumor cells are frequently arrangemed around blood vessels (f; asterisks), do not contain rosenthal fibers and show a predominant myxoid matrix ( $g$ ). a, $c-f$; hematoxylin-eosin (HE); b, g; alcian-blue $(A B)$. Original magnifications: $a-c, f, g: x 100$; d, e: $x 400$. increased cellularity, nuclear abnormalities, increased mitotic activity and palisading necrosis (Figure 1c-e), resulting in the diagnosis of an anaplastic pilocytic astrocytoma (corresponding to WHO grade III) was confirmed by reference pathology ${ }^{3}$. Pilomyxoid astrocytoma (WHO grade II) is histologically closely related to PA and was distinguished from PA by a prominent mucoid matrix, an angiocentric arrangement of bipolar tumor cells as well as the lack of Rosenthal fibers and eosinophilic granular bodies (Figure $1 \mathrm{f}-\mathrm{g})^{1,3}$. One PMA with anaplastic features such as increased numbers of mitoses, higher cellularity and necrosis was classified as anaplastic PMA corresponding to WHO grade III. Histopathological diagnosis was confirmed by reference pathology in 25/40 cases, including all PMAs and both tumors with anaplastic features corresponding to WHO grade III.

The myxoid tumor matrix was estimated on the basis of alcian-blue staining (highlighting acid mucosubstances and acetic mucins) and was noted in each case as the approximat percentage of the whole tumor area $(0-100 \%)$. Tumors were grouped in a 4-point scale with group 1 having $<25 \%$ myxoid tumor matrix; Group 2 having 25-49\% myxoid tumor matrix; Group 3 having 50-74\% myxoid tumor matrix; Group 4 having
$>=75 \%$ myxoid tumor matrix. Myxoid content was correlated with $\mathrm{T} 2 / \mathrm{CSF}$ and $\mathrm{ADC} / \mathrm{CSF}$ ratios. Additionally patients were divided into two groups: One with less and the other with more than $50 \%$ myxoid tumor matrix content. However sufficient pathologic material for this scoring was available only in 8 PMA and $17 \mathrm{PA}$. Cases in which only very small tissue samples were available for histological examinations were excluded from the quantification of the myxoid tumor matrix.

\section{Statistical analysis}

All continuous values are presented as mean \pm standard deviation. Differences between PA and PMA for measured ADC and $\mathrm{T} 2$ values (as well as for the respective ratios to CSF) were determined by student's t-test, after normal distribution of the data was ascertained using a Kolmogorov-Smirnov test. A ROC analysis was performed in order to determine the optimal threshold to discriminate between PA and PMA. The critical cutoff value was selected to maximize diagnostic accuracy (i.e. minimize false negative and positive results). Sensitivity and specificity are given for this threshold. Differences between the two observers were tested using a paired student's t-test. 
Correlation of $\mathrm{T} 2 / \mathrm{CSF}, \mathrm{ADC} / \mathrm{CSF}$ and $\mathrm{ADC}$ values with the score of grouped myxoid content was assessed using Pearson's correlation. The groups with more and less than 50\% myxoid content were compared using student's t-test. Differences were considered statistically significant for $\mathrm{p}$ less than 0.05 . The statistical tests were performed using SPSS Version 11.0 (SPSS Inc., Chicago, IL).

\section{RESULTS}

\section{Standard MR imaging features}

Tumor localisations and standard imaging features are listed in Table 1. The MR signal was always (100\%) hyperintense on T2-weighted and FLAIR images. Slight perifocal edema was only seen in one case of PMA and was absent in all other cases of PA and PMA. In the sole case of WHO grade III anaplastic PA, imaging parameters, including ADC values, did not differ from those of WHO grade I PAs.

In PMA neither quantity, nor quality of enhancement correlated in any way with the myxoid content.

\section{Signal measurements}

All measurements were performed by two independent observers. There was no significant difference between T2 $(\mathrm{p}=0.36)$ and $\mathrm{ADC}(0.35)$ measurements of the observers. Likewise, correlation between those measurements was high yielding $\mathrm{r}^{2}=0.81$ for $\mathrm{T} 2$ and $\mathrm{r}^{2}=0.96$ for ADC measurements. Subsequently mean values of both observers are given.

\section{T2 signal quantification}

Signal intensity measurements in solid tumor parts on T2weighted images yielded median values of $672.2 \pm 208.9$ (95\% confidence intervals (CI) 599-745) a.u. for PA and 828.7 \pm 147.0 (95\% CI 693-965) a.u. for PMA, respectively ( $\mathrm{p}<0.05)$. Mean T2/CSF ratio for PA and PMA was $0.78 \pm 0.19$ (95\% CI 0.72$0.85)$ and $0.93 \pm 0.09(95 \% \mathrm{CI} 0.85-1.02)(\mathrm{p}<0.01)$. The optimal threshold for the T2/CSF ratio was determined to be 0.76 (yielding a sensitivity of $100 \%$ and specificity of $52.9 \%$ ). Figures 2a-d and 3a-d illustrate both tumor entities and their T2, DWI-, and ADC signals.

\section{$A D C$ values}

Mean ADC values for PA and PMA were $1.67 \pm 0.32 \times 10^{-3}$ (95\% CI 156-179) $\mathrm{mm}^{2} / \mathrm{sec}$ and $1.98 \pm 0.19(95 \%$ CI 180-216) x $10^{-3} \mathrm{~mm}^{2} / \mathrm{sec}$, respectively $(\mathrm{p}<0.01)$. Interobserver variability was not-significant, $(\mathrm{p}=0.35)$. Mean ADC/CSF ratio for PA and PMA was $0.53 \pm 0.10(95 \%$ CI $0.49-0,57)$ and $0.69 \pm 0.10,(95 \%$ CI 0.60-0.76) respectively ( $\mathrm{p}<0.01)$ (Figures $4-6)$.

The optimal threshold for ADC values to discriminate between PA and PMA was $1.76 \times 10^{-3} \mathrm{~mm}^{2} / \mathrm{sec}$ (yielding a sensitivity of $100 \%$ and a specificity of $65.6 \%$ ), whereas the optimal threshold for differentiation between the two neoplasms based on $\mathrm{ADC} / \mathrm{CSF}$ ratio was determined to be 0.56 (yielding a sensitivity of $100 \%$ and specificity of $59.4 \%$ ).

\section{Histological semiquantification of myxoid matrix content}

The myxoid tumor content was distributed normally and yielded a median of 90\% (mean 93\%, range, 90-100\%) for PMA

Table 1: Standard imaging features of pilomyxoid astrocytoma (PA) and pilocytic astrocytoma (PMA)

\begin{tabular}{|c|c|c|c|c|c|c|c|c|}
\hline & localisation & $\begin{array}{l}\text { T1 } \\
\text { hypo }\end{array}$ & $\begin{array}{l}\mathrm{T} 1 \\
\text { iso }\end{array}$ & $\begin{array}{l}\text { T1 } \\
\text { hyper }\end{array}$ & $\begin{array}{l}\text { Gd } \\
\text { no }\end{array}$ & $\begin{array}{l}\text { Gd } \\
\text { mild }\end{array}$ & $\begin{array}{l}\mathrm{Gd} \\
\text { strong }\end{array}$ & $\begin{array}{l}\text { macrocystic } \\
\text { tumor parts }\end{array}$ \\
\hline \multirow[t]{6}{*}{$\mathrm{PA}$} & cerebellar $(n=18)$, & $\mathrm{n}=17$ & - & $\mathrm{n}=1$ & - & $\begin{array}{l}n=3 \\
1 \text { ho. } \\
2 \text { he. }\end{array}$ & $\begin{array}{l}n=15 \\
5 \text { ho. } \\
10 \text { he. }\end{array}$ & $\begin{array}{l}n=15 \\
8 \text { mild } \\
7 \text { moderate }\end{array}$ \\
\hline & supra-/parasellar $(n=6)$, & $\mathrm{n}=5$ & $\mathrm{n}=1$ & - & - & $\begin{array}{l}\mathrm{n}=3 \\
1 \text { ho. } \\
2 \text { he. }\end{array}$ & $\begin{array}{l}\mathrm{n}=3 \\
1 \text { ho. } \\
2 \text { he. }\end{array}$ & $\mathrm{n}=1$ mild \\
\hline & $\begin{array}{l}\text { supratentorial lobar } \\
(\mathrm{n}=8)\end{array}$ & $\mathrm{n}=6$ & $\mathrm{n}=2$ & - & $\begin{array}{l}\mathrm{n}=1 \\
1 \text { he. }\end{array}$ & $\begin{array}{l}\mathrm{n}=4 \\
2 \text { ho. } \\
2 \text { he. }\end{array}$ & $\begin{array}{l}\mathrm{n}=3 \\
3 \text { he. }\end{array}$ & $\mathrm{n}=5$ mild \\
\hline & pontine $(\mathrm{n}=1)$ & - & $\mathrm{n}=1$ & - & $\mathrm{n}=1$ & - & - & - \\
\hline & spinal $(n=1)$ & $\mathrm{n}=1$ & - & - & - & - & $\begin{array}{l}\mathrm{n}=1 \\
1 \text { he. }\end{array}$ & $\mathrm{n}=1$ mild \\
\hline & sum of all PA $(n=34)$ & $\begin{array}{l}\mathrm{n}=29 \\
(85 \%)\end{array}$ & $\mathrm{n}=4(12 \%)$ & $\begin{array}{l}\mathrm{n}=1 \\
(3 \%)\end{array}$ & $\mathrm{n}=2(6 \%)$ & $\mathrm{n}=10(32 \%)$ & $\begin{array}{l}\mathrm{n}=22 \\
(62 \%)\end{array}$ & $\mathrm{n}=17(50 \%)$ \\
\hline \multirow[t]{3}{*}{ PMA } & supra-/parasellar $(\mathrm{n}=5)$ & $\mathrm{n}=4$ & $\mathrm{n}=1$ & - & & & $\begin{array}{l}\mathrm{n}=5 \\
3 \text { ho. } \\
2 \text { he. }\end{array}$ & $\mathrm{n}=1$ mild \\
\hline & $\begin{array}{l}\text { supratentorial lobar } \\
(\mathrm{n}=3)\end{array}$ & $\mathrm{n}=3$ & - & - & $\begin{array}{l}\mathrm{n}=1 \\
1 \text { he. }\end{array}$ & $\begin{array}{l}\mathrm{n}=1 \\
1 \text { he. }\end{array}$ & $\begin{array}{l}\mathrm{n}=1 \\
1 \text { he. }\end{array}$ & $\begin{array}{l}\mathrm{n}=3 \\
1 \text { mild } \\
1 \text { moderate } \\
1 \text { entirely cysti }\end{array}$ \\
\hline & Sum of all PMA $(\mathrm{n}=8)$ & $\mathrm{n}=7(88 \%)$ & $\mathrm{n}=1(13 \%)$ & - & $\mathrm{n}=1(13 \%)$ & $\mathrm{n}=1(13 \%)$ & $\mathrm{n}=6(75 \%)$ & $\mathrm{n}=17(50 \%)$ \\
\hline
\end{tabular}

hypo=hypointense, iso=isointense, hyper=hyperintense, $\mathrm{Gd}=$ gadoliniumenhancement, he.=heterogeneous, ho.=homogeneous 

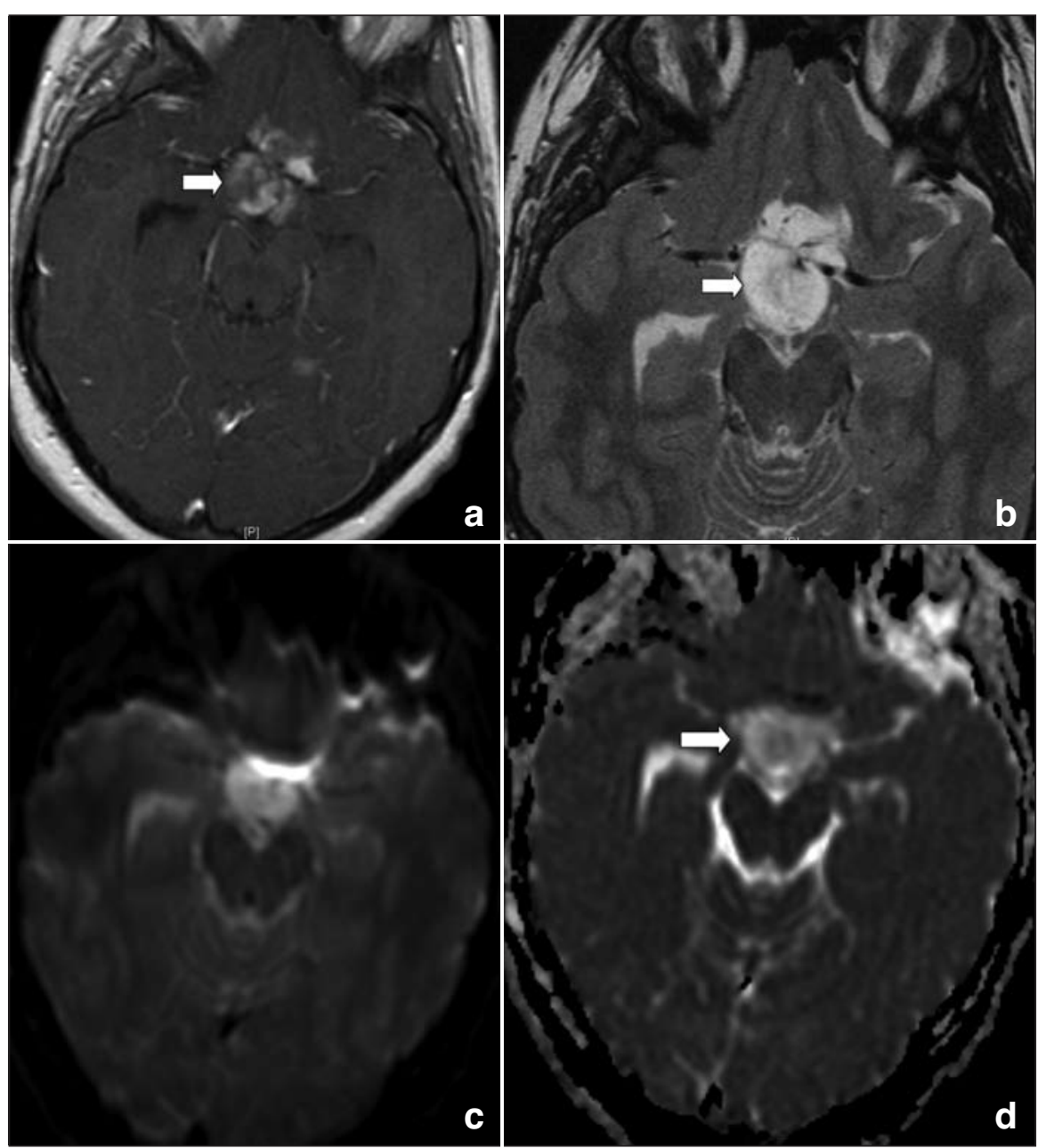

Figure 2: Nine year-old boy with histologically proven suprachiasmatic PMA before neurosurgery. Axial post-contrast T1weighted image shows heterogeneously increased tumor enhancement (arrow) (2a). Both on the transversal T2-weighted TSE image (2b) as well as on the transversal DWI $\left(b\right.$-value, $\left.500 \mathrm{~s} / \mathrm{mm}^{2}, 2 c\right)$ the suprachiasmatic PMA encasing the internal carotid artery and anterior cerebral artery demonstrates hyperintense signal, but there was no restriction of water diffusivity on the corresponding $A D C$-map (2d). ADC and T2 signal quantification yielded the following values: $A D C, 1.80 \pm 0.3 \times 10^{3} \mathrm{~mm}^{2} / \mathrm{sec}$, ADC/CSF ratio 0.606, T2 signal $808.2 \pm 0.3$ and $T 2 / C S F$ ration 0.95 . and a median of $55 \%$ (mean $50 \%$, range, 10-100\%) for PA $(\mathrm{p}=0.004)$. Only 1 patient with PA had an entirely myxoid tumor matrix $(100 \%)$.

There was moderately good correlation of myxoid content with T2/CSF, ADC/CSF and ADC yielding $\mathrm{r}^{2}=0.61, \mathrm{r}=0.65$, and $r^{2}=0.60$ respectively. Both, T2 and ADC ratios as well as $\mathrm{ADC}$ values were significantly higher in tumors with more than $50 \%$ myxoid content as outlined in Table 2.

\section{Discussion}

The purpose of this study was to assess the discriminatory potential of T2 and ADC quantification in both PA and its new histological variant, the PMA. Knowingly, standard imaging features of PA and PMA do not significantly differ from each other. In accordance with results published recently by Linscott et al. T2 and FLAIR signal was hyperintense in all tumors, T1 signal was hypointense in the majority of cases and contrast enhancement proved variable in both entities ${ }^{5}$. Whereas up to

Table 2: Correlation of T2/CSF, ADC/CSF ratios and ADC values with the content of tumor myxoid matrix

\begin{tabular}{|c|c|c|c|c|c|}
\hline & \multicolumn{2}{|c|}{ less than $50 \%$ myxoid content } & \multicolumn{2}{|c|}{ more than $50 \%$ myxoid content } & \multirow[t]{2}{*}{$\mathrm{p}$} \\
\hline & mean & (95\% confidence intervals) & mean & (95\% confidence intervals) & \\
\hline T2/CSF & 0.74 & $(0.63-0.85)$ & 0.91 & $(0.65-0.85)$ & 0.01 \\
\hline $\mathrm{ADC} / \mathrm{CSF}$ & 0.49 & $(0.40-0.57)$ & 0.62 & $(0.47-0.59)$ & 0.01 \\
\hline ADC & 155.74 & $(122-188)$ & 185.53 & $(150-188)$ & 0.02 \\
\hline
\end{tabular}



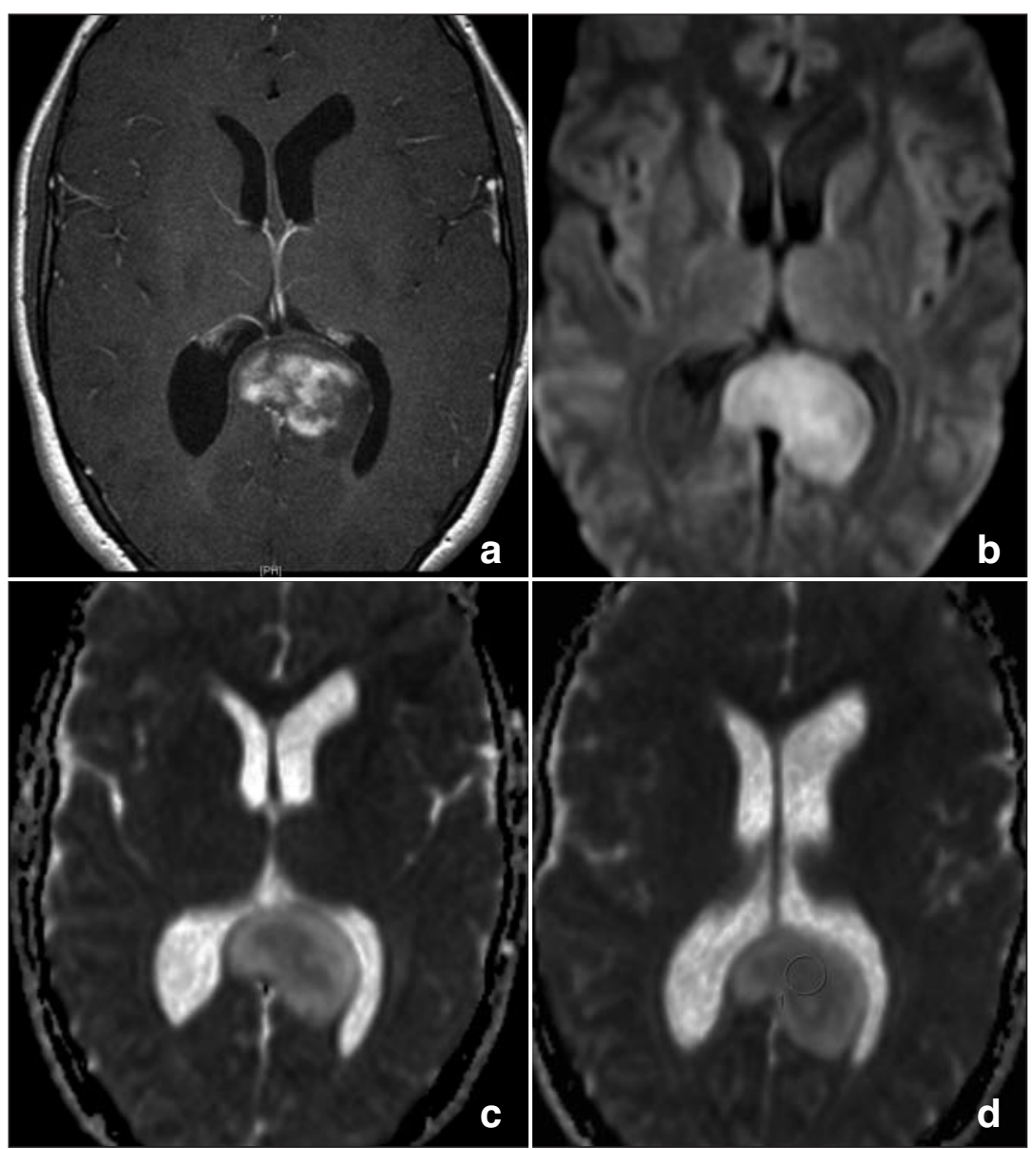

Figure 3: Six year-old female with histologically proven pilocytic astrocytoma (WHO grade I). Note heterogeneous enhancement of the mass in the splenium of the corpus callosum on axial post-contrast T1weighted image (3a). Note high signal intensity on both DWI with a b-value of $500 \mathrm{~s} / \mathrm{mm}^{2}(3 \mathrm{~b})$ and T2-weighted image ( $3 c)$, but no apparent water restriction on $A D C$ map (3d). Nevertheless, measured ADC values in the core of this lesion were comparably lower, presumably due to more densely packed cells. ADC and T2 signal quantification yielded following values: $A D C, 1.61 \pm$ $0.1 \times 10^{-3} \mathrm{~mm}^{2} / \mathrm{sec}, \mathrm{ADC} / \mathrm{CSF}$ ratio 0.53, T2 signal $819.9 \pm 0.2$ and $T 2 / C S F$ ration 0.98 .

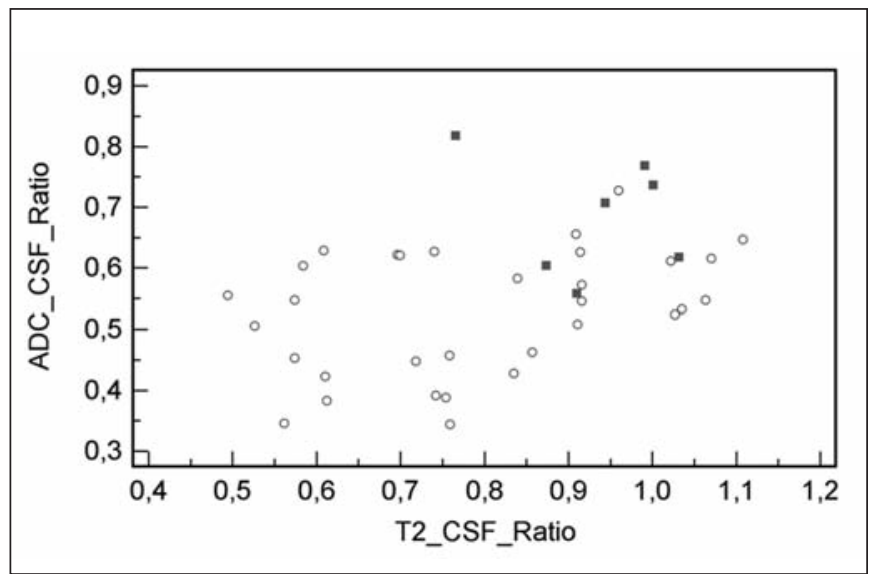

Figure 4: Scatter plot illustrating the distribution of T2/CSF and ADC/CSF ratios. Squares representing pilomyxoid astrocytoma and rings representing pilocytic astrocytoma

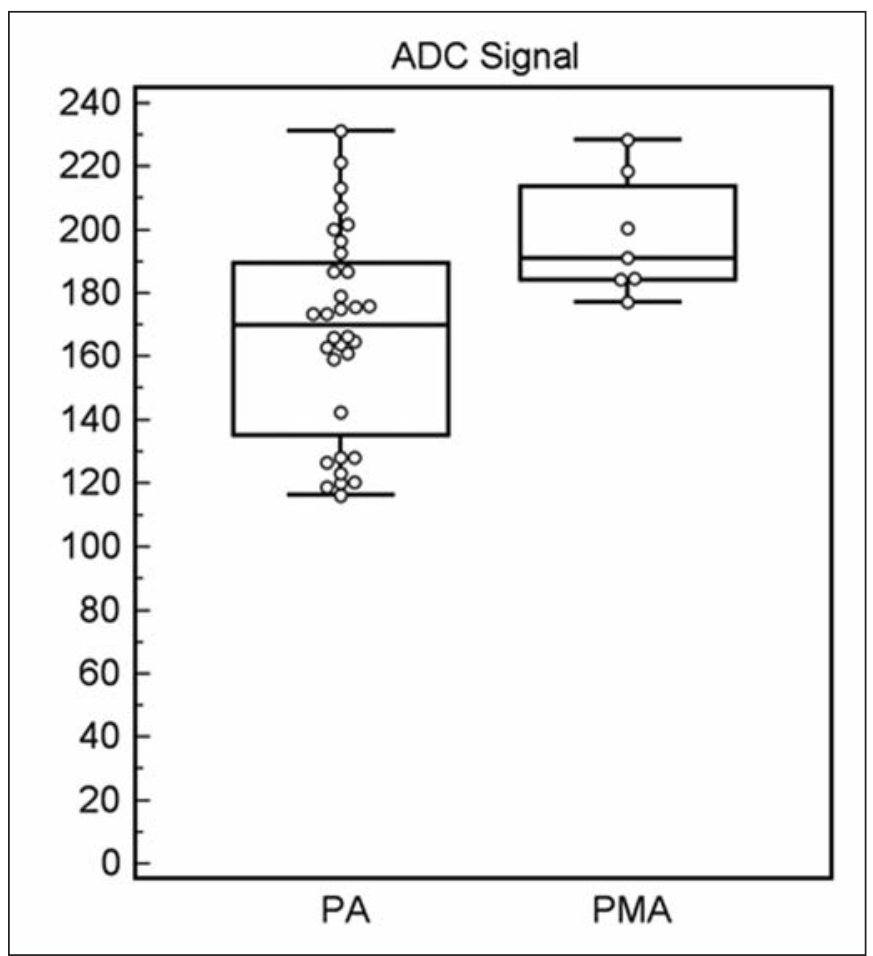

Figure 5: Box plot representing the distribution of $A D C$ signal intensity in pilocytic and pilomyxoid astrocytoma. 


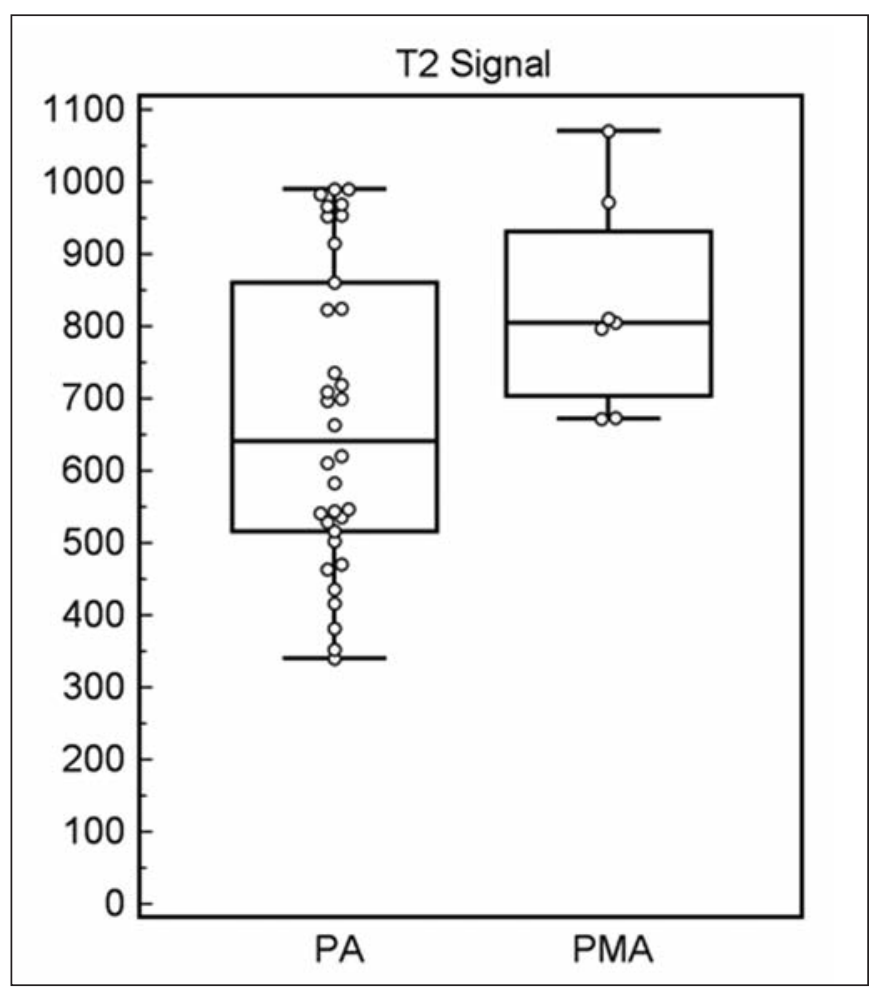

Figure 6: Box plot representing the distribution of $T 2$ signal intensity in pilocytic and pilomyxoid astrocytoma.

$50 \%$ of PA behave characteristically with respect to standard MRI findings, demonstrating an admixture of solid and macrocystic tumor parts as well as strong heterogeneous contrast enhancement and lack of peritumoral edema, the other $50 \%$, in particular, those occurring in adults, exhibit nonspecific findings that can be challenging for the neuroradiologist in the daily diagnostic work up. As standard morphologic MRI found in the latter group, might be equivocal, information on cellularity and tumor stroma as provided by DWI might still prove helpful for differentiation of PA and PMA. In PMA T2 and ADC values are expected to be markedly increased, due to more abundant myxoid tumor matrix ${ }^{9,12}$. Our study confirms the trend of higher ADC values and increased T2 signal intensity present in PMA compared to PA. However, there was still considerable overlap between PMA from PA impeding reliable differentiation. These results are in line with previous data stating that DWI could represent an important discriminator of PA and PMA from each other and from potential differential diagnoses due to the lack of restriction in water diffusivity $7,8,11$. Data with respect to the role of DWI in characterizing posterior fossa tumors have been published, highlighting its benefit, especially in differentiating medulloblastoma from $\mathrm{PA}^{12}$. However, these data are based on a small patient series, and the recently described variant of PA, the PMA, has not yet been analyzed with respect to quantification of ADC values as compared to PA.

In this study, we assessed ADC values and T2 signal characteristics of PA and PMA for more accurate characterization and potential differentiation of these two pathologic subtypes, as the latter is known for its more aggressive character ${ }^{10,11}$. ADC values were determined in the solid tumor parts presenting the lowest ADC values regardless of whether the MR imaging characteristics were deemed typical or atypical for PA or presented as entirely solid or solid-cystic. We could demonstrate that no patient diagnosed with either PA or PMA in our series revealed restriction of water diffusivity. This was also true in patients with atypical PA-presentation. Restriction of water diffusivity in some PA as a consequence of hemorrhage, calcification or possibly reflecting histologic variability of these tumors has been reported, but this was not supported by our data ${ }^{13}$. However, focal signs of previous hemorrhage (siderophages) are histologically not uncommon in $\mathrm{PA}^{3}$. However, macroscopic areas of acute haemorrhage are extremely rare in $\mathrm{PA}^{13}$. Expectedly, our study yielded higher mean ADC values for PMA than for PA. Considering data in the literature about ADC in other pediatric cerebellar tumors, values above $1.30 \times 10^{-3} \mathrm{~mm}^{2} / \mathrm{sec}$ can characterize PMA versus medulloblastoma, ependymoma and atypical theratoid/rhabdoid tumors $^{12}$. However four of our patients with PA presented with absolute ADC values below $1.30 \times 10^{-3} \mathrm{~mm}^{2} / \mathrm{sec}$. This result corroborates only partially with measurements reported by Rumboldt et $\mathrm{al}^{12}$ who found ADC values above $1.40 \times 10^{-3}$ $\mathrm{mm}^{2} / \mathrm{sec}$ for all PA of their series. Moreover PA with ADC values below $1.30 \times 10^{-3} \mathrm{~mm}^{2} / \mathrm{sec}$ cannot be differentiated from other tumors (e.g. ependymoma) based solely on DWI measurements ${ }^{12}$.

The interobserver agreement was substantial for all parameters. Imaging results correlate well with those of the histological analysis in the subgroup of patients where suitable macroscopic tumor probes could retrospectively be evaluated, suggesting a major role of the amount of myxoid background on both T2 signal intensity and water diffusivity. Finally, differentiation between PA and PMA on the basis of ADC values is not absolutely confident due to significant overlap. However higher ADC and T2 signal intensity suggests the presence of PMA, particularly in the appropriate clinical setting (e.g. younger patient, etc.). Due to their different behaviour, prioritising PA or PMA could be of interest for the treating physician. Although histological proof is required for treatment, the initial management of these tumors can be different.

Our study holds some limitations. One of them comprises the different sizes of the analyzed tumor groups which makes determination of thresholds for absolute ADC values, T2/CSF and $\mathrm{ADC} / \mathrm{CSF}$ difficult. The statistical analysis would have been more robust if both tumor samples had been similar in size. Another limitation of this study was its retrospective character. Furthermore only a subgroup of PA patients could be included for histological correlation due to the unavailability of macroscopic histological probes in patients that were investigated at other pathology- institutes.

\section{Conclusions}

While general imaging features of PA and PMA are nonspecific, measured ADC values and T2 signal intensities are generally higher in the latter, reflecting the proportion of myxoid matrix in these tumors. The use of an ADC/CSF ratio $<0.5$ could rule out PMA in our cohort. 


\section{REFERENCES}

1. Fuller C, Narendra S. Pilocytic astrocytoma and pilomyxoid astrocytoma. In: Adesina AM, Tihan T, Young Pouissant T, editors. Atlas of pediatric brain tumors (Pt 1). New York: Dordrecht, Heidelberg, London; Springer; 2010. p. 5-17.

2. Lee YY, Van Tassel P, Bruner JM, Moser RP, Share JC. Juvenile pilocytic astrocytomas: CT and MR characteristics. Am J Roentgenol. 1989;152:1263-70.

3. Scheithauer BW, Hawkins C, Tihan T, Van den Berg SR, Burger PC. Pilocytic astrocytoma. In: Louis DN, Ohgaki H, Wiestler OD, Cavenee WK, editors WHO Classification of tumours of the central nervous system. 4th ed. Lyon, France: IARC Press; 2007. p. 14-21.

4. Arslanoglu A, Cirak B, Horska A, et al. MR imaging characteristics of pilomyxoid astrocytomas. Am J Neuroradiol. 2003;24: 1906-8.

5. Linscott LL, Osborn AG, Blaser S, et al. Pilomyxoid astrocytoma: expanding the imaging spectrum. Am J Neuroradiol. 2008;29: 1861-6.

6. Lee $\mathrm{IH}$, Kim JH, Suh YL, et al. Imaging characteristics of pilomyxoid astrocytomas in comparison with pilocytic astrocytomas. Eur J Radiol. 2011;79(2):311-16.

7. Krabbe K, Gideon P, Wagn P, Hansen U, Thomsen C, Madsen F. MR diffusion imaging of human intracranial tumours. Neuroradiology. 1997;39:483-9.
8. Sugahara T, Korogi Y, Kochi M, et al. Usefulness of diffusionweighted MRI with echo-planar technique in the evaluation of cellularity in gliomas. J Magn Reson Imaging. 1999;9:53-60.

9. Komotar RJ, Zacharia BE, Sughrue ME, et al. Magnetic resonance imaging characteristics of pilomyxoid astrocytoma. Neurol Res. 2008;30(9):945-51.

10. Toh CH, Castillo M, Wong AMC, et al. Primary cerebral lymphoma and glioblastoma multiforme: differences in diffusion characteristics evaluated with diffusion tensor imaging. Am $\mathbf{J}$ Neuroradiol. 2008;29:471-5.

11. Tihan T, Fisher PG, Kepner JL, et al. Pediatric astrocytomas with monomorphous pilomyxoid features and a less favorable outcome. J Neuropathol Exp Neurol. 1999;58(10):1061-8.

12. Rumboldt Z, Camacho DL, Lake D, Welsh CT, Castillo M. Apparent diffusion coefficients for differentiation of cerebellar tumors in children. Am J Neuroradiol. 2006;27(6): 1362-9.

13. Lee CS, Huh JS, Sim KB, Kim YW. Cerebellar pilocytic astrocytoma presenting with intratumor bleeding, subarachnoid hemorrhage, and subdural hematoma. Childs Nerv Syst. 2009; 25(1): $125-8$. 